\title{
Article
}

\section{Hierarchically skeletal multi-layered Pt-Ni nanocrystals for highly efficient oxygen reduction and methanol oxidation reactions}

\author{
Shibo Li a,b , Zhi Qun Tian a,b, Yang Liu a,b, Zheng Jang a, Syed Waqar Hasan a , Xingfa Chen a , \\ Panagiotis Tsiakaras c,d,e,*, Pei Kang Shen a,b,\# \\ a Collaborative Innovation Center of Sustainable Energy Materials, Guangxi Key Laboratory of Electrochemical Energy Materials, School of Chemistry and \\ Chemical Engineering, Guangxi University, Nanning 530004, Guangxi, China \\ b Key Laboratory of New Processing Technology for Non-ferrous Metal and Materials, Ministry of Education, Guangxi University, Nanning 530004, \\ Guangxi, China \\ c Institute of High Temperature Electrochemistry, RAS, Yekaterinburg 620990, Russia \\ d Ural Federal University, 19 Mira Str., Yekaterinburg 620002, Russia \\ e Laboratory of Alternative Energy Conversion Systems, Department of Mechanical Engineering, University of Thessaly, Pedion Areos 38834, Greece
}

\section{A R T I C L E I N F O}

\section{Article history:}

Received 11 May 2020

Accepted 20 June 2020

Available online 5 September 2020

\section{Keywords:}

Hierarchically skeletal Pt-Ni

nanocrystals

Self-assembly

Solvent thermal method

Oxygen reduction reaction

Methanol oxidation reaction

Fuel cells

Activity

\begin{abstract}
A B S T R A C T
Pt based materials are the most efficient electrocatalysts for the oxygen reduction reaction (ORR) and methanol oxidation reaction (MOR) in fuel cells. Maximizing the utilization of Pt based materials by modulating their morphologies to expose more active sites is a fundamental objective for the practical application of fuel cells. Herein, we report a new class of hierarchically skeletal Pt-Ni nanocrystals (HSNs) with a multi-layered structure, prepared by an inorganic acid-induced solvothermal method. The addition of $\mathrm{H}_{2} \mathrm{SO}_{4}$ to the synthetic protocol provides a critical trigger for the successful growth of Pt-Ni nanocrystals with the desired structure. The Pt-Ni HSNs synthesized by this method exhibit enhanced mass activity of $1.25 \mathrm{~A} \mathrm{mgpt}^{-1}$ at $0.9 \mathrm{~V}$ (versus the reversible hydrogen electrode) towards ORR in 0.1-M $\mathrm{HClO}_{4}$, which is superior to that of Pt-Ni multi-branched nanocrystals obtained by the same method in the absence of inorganic acid; it is additionally 8.9-fold higher than that of the commercial Pt/C catalyst. Meanwhile, it displays enhanced stability, with only $21.6 \%$ mass activity loss after 10,000 cycles $(0.6-1.0 \mathrm{~V})$ for ORR. Furthermore, the Pt-Ni HSNs show enhanced activity and anti-toxic ability in CO for MOR. The superb activity of the Pt-Ni HSNs for ORR and MOR is fully attributed to an extensively exposed electrochemical surface area and high intrinsic activity, induced by strain effects, provided by the unique hierarchically skeletal alloy structure. The novel open and hierarchical structure of Pt-Ni alloy provides a promising approach for significant improvements of the activity of Pt based alloy electrocatalysts.
\end{abstract}

(C) 2021, Dalian Institute of Chemical Physics, Chinese Academy of Sciences. Published by Elsevier B.V. All rights reserved.

\section{Introduction}

Fuel cells are among the most promising clean power sources for electric vehicles and electronic devices [1-3]. The

\footnotetext{
* Corresponding author. E-mail: tsiak@mie.uth.gr

\# Corresponding author. E-mail: pkshen@gxu.edu.cn

This work was supported by the National Key Research and Development Plan (2017YFB0103001), the link project of the National Natural Science Foundation of China and Fujian Province (U1705252), the Guangxi Science and Technology Projects (AA17204083, AB16380030), the innovation project of Guangxi Graduate Education (YCBZ2019012).

DOI: 10.1016/S1872-2067(20)63680-4 | http://www.sciencedirect.com/science/journal/18722067 | Chin. J. Catal., Vol. 42, No. 4, April 2021
} 
electrocatalysis of Pt catalysts for oxygen reduction reaction (ORR) [4] and methanol oxidation reaction (MOR) [5] play a vital role in determining the energy efficiency of systems. Moreover, they also greatly influence the overall cost of fuel cells due to their high cost, caused by Pt resource scarcity. Therefore, a critical aspect of fuel cell manufacture is the design of highly efficient electrocatalysts, which would maximize the utilization rate of $\mathrm{Pt}$, thus reducing $\mathrm{Pt}$ loading. Previous studies have shown that alloying Pt with transition metals can effectively improve electro-catalytic performances [6], and the composition and morphology of the generated alloys are critical parameters that influence the catalytic activity [3,7-9].

To date, a plethora of Pt-based catalysts have been explored, such as $\mathrm{Pt}-\mathrm{Pb} / \mathrm{Pt}$ core/shell nanoplates [10], excavated $\mathrm{Pt}_{3} \mathrm{Co}$ nanocubes [11], Pt-Cu-Rh heterogeneous nanocages [12], hollow Pt-Ag nanocrystals [13], Pt-Pd nanodendrites [14], Pt-Ni nanoframes [15], among others. These catalysts have exhibited significant improvements in electrochemical activity and stability, compared with the commercial Pt/C catalyst for ORR or MOR. For example, the Pt-Pd bimetallic nanodendrites resulted in a 7.8-fold enhancement in mass activity and remarkable durability compared to Pt, due to the large specific surface area of nanodendrite structures, which favor mass and electron transport [14]. However, the cost of Pd is significantly higher than that of other transition metals (such as $\mathrm{Cu}, \mathrm{Ni}, \mathrm{Co}, \mathrm{Pb}, \mathrm{Ag}$ ), which reduces its feasibility, in spite of it being an excellent electrocatalyst. Compared to other reported Pt-based catalysts, Pt-Ni alloys are among the most promising electro-chemical catalysts because they exhibit excellent catalytic performances for ORR in PEMFCs, and Ni is widely available at a low cost [16-20]. For example, Pt-Ni alloy hyperbranched nanostructures showed enhanced mass activity compared to that of state-of-the-art Pt electrocatalysts [21]. Based on these results, the fabrication of a Pt-Ni alloy with a large accessible surface area would be beneficial, as it is expected to provide an excellent electrochemical performance and stability at a relatively low cost.

Herein, we report a new class of hierarchically skeletal Pt-Ni nanocrystals with a multi-layered structure, prepared via a facile solvothermal method, utilizing the $\mathrm{H}_{2} \mathrm{SO}_{4}$-driven self-assembly effect. The hierarchically skeletal Pt-Ni nanocrystals (HSNs) provide a large specific surface area of the Pt \{111\} facet and simultaneously possess a well-defined self-supported structure, which facilitates electron transport and prevents morphological changes in the long-duration electrochemical test. Remarkably, the Pt-Ni HSNs exhibit an extremely prominent mass activity and superior durability toward ORR compared with the commercial Pt/C catalyst, apart from exhibiting an enhanced catalytic activity for MOR.

\section{Experimental}

\subsection{Chemicals}

All chemicals were purchased from Macklin, including chloroplatinic acid hexahydrate $\left[\mathrm{H}_{2} \mathrm{PtCl}_{6} \cdot 6 \mathrm{H}_{2} \mathrm{O}\right]$, nickel acetate tetrahydrate $\left[\mathrm{Ni}\left(\mathrm{CH}_{3} \mathrm{COO}\right)_{2} \cdot 4 \mathrm{H}_{2} \mathrm{O}, 99 \%\right]$, oleylamine (OAM,
80\%-90\%), cetyltrimethyl ammonium chloride (CTAC, 97\%), and sulfuric acid $\left(\mathrm{H}_{2} \mathrm{SO}_{4}, 98 \%\right)$. The chemicals were used as-received in the experiments. In addition, ultrapure deionized water (18.2 $\mathrm{M} \Omega$ ) was used in the experiments.

\subsection{Synthesis of Pt-Ni hierarchically skeletal nanocrystals (HSNs)}

First, $5 \mathrm{mg}$ of $\mathrm{H}_{2} \mathrm{PtCl}_{6} \cdot 6 \mathrm{H}_{2} \mathrm{O}$ and $1 \mathrm{~mL}$ of $\mathrm{H}_{2} \mathrm{SO}_{4}$ (1 M) were mixed together, with the removal of as much moisture as possible under vacuum drying. Next, $10 \mathrm{mg}$ of $\mathrm{Ni}\left(\mathrm{CH}_{3} \mathrm{COO}\right)_{2} \cdot 4 \mathrm{H}_{2} \mathrm{O}$, and $150 \mathrm{mg}$ of CTAC were dissolved sequentially into $10 \mathrm{~mL}$ of OAM under magnetic stirring, and the mixed solution was transferred into a $25 \mathrm{~mL}$ Teflon-lined stainless steel autoclave for solvothermal synthesis. The autoclave was then placed in an oil bath and heated at $160{ }^{\circ} \mathrm{C}$ for $20 \mathrm{~h}$ under continuous stirring. The reaction was then cooled to room temperature and the resultant black slurry was collected by centrifugation and washed five times with ethanol, which was followed by acid-leaching treatment using $10 \mathrm{~mL}$ of acetic acid at $80^{\circ} \mathrm{C}$ for $5 \mathrm{~h}$, to remove the unstable $\mathrm{Ni}$ component. The final samples were obtained after thorough washing and drying.

The Pt-Ni multi-branched catalysts (MBs) were prepared via the same method, with the exception of $\mathrm{H}_{2} \mathrm{SO}_{4}$ addition for comparison.

\subsection{Preparation and activation of carbon-supported catalysts}

In a typical preparation, $5.0 \mathrm{mg}$ of carbon powder (Vulcant-72) and $3.0 \mathrm{mg}$ of Pt-Ni HSNs or MBs were dispersed in 20 $\mathrm{mL}$ of $n$-butylamine and ultra-sonicated for $1 \mathrm{~h}$, followed by stirring at room temperature for $72 \mathrm{~h}$. Next, the product was collected by centrifugation, followed by washing two times with methanol and three times with ethanol to remove excessive $n$-butylamine, and then dried at $80{ }^{\circ} \mathrm{C}$ in a vacuum oven overnight. Lastly, the samples were activated in a furnace at $200{ }^{\circ} \mathrm{C}$ for $2 \mathrm{~h}$ in air, to remove residual organic compounds such as oleylamine or CTAC and to anneal the catalysts.

\subsection{Materials characterization}

High resolution transmission electron microscopy (HRTEM), conducted with a TITAN G2 microscope (FEI, American) at an accelerating voltage of $300 \mathrm{KV}$, and scanning electron microscopy (SEM), employing the SU8220 microscope (Hitachi, Japan), were employed to observe the fine structure of the samples. The sample chemical composition was obtained by X-ray photoelectron spectroscopy (XPS), equipped with monochromatic Al $K_{\alpha}$ sources (ESCAL ab 250, USA). The Pt content in the slurry was measured by inductively coupled plasma atomic emission spectroscopy (ICP, TJA RADIAL IRIS 1000 ICP-AES, USA).

\subsection{Electrochemical measurements}

Electrochemical measurements were performed in a three-electrode electrochemical cell using a pine rotational 
ring-disk electrode (RRDE) system connected to a bipotentiostat (AFCBP1E, Pine Instrument Co. USA). A glassy carbon $\left(0.2475 \mathrm{~cm}^{-2}\right.$ in a geometric area) covered with a thin catalyst film acted as the working electrode. A reversible hydrogen electrode (RHE) and a carbon rod were used as the reference and counter electrode, respectively. To prepare working electrodes for the catalytic tests, $2.0 \mathrm{mg}$ of Pt-Ni HSNs on carbon, Pt-Ni MBs on carbon and commercial Pt/C catalyst (TKK, Japan) were ultrasonically dispersed in $2.0 \mathrm{~mL}$ of a mixed solution of $1.8 \mathrm{~mL}$ of ethanol and $200 \mu \mathrm{L}$ of $0.5 \mathrm{wt} \%$ Nafion solution. A $10 \mu \mathrm{L}$ aliquot of the corresponding catalyst ink was transferred onto the clean glassy carbon surface to form a homogenous thin film in air, using a micropipette. The precious Pt loading on the working electrode could be calculated using measured Pt contents in the catalyst ink, obtained by ICP-AES. The Pt loading of Pt-Ni HSNs, Pt-Ni MBs and TKK-Pt/C was $15.31,14.98$ and $17.6 \mu \mathrm{g} \mathrm{cm}^{-2}$, respectively. Prior to testing, the electrodes were electrochemically activated by sweeping from 0.05 to $1.10 \mathrm{~V}$ versus RHE in $\mathrm{N}_{2}$-saturated $0.1 \mathrm{M} \mathrm{HClO}_{4}$ solution at a scan rate of $100 \mathrm{mV} \mathrm{s}^{-1}$. Cyclic voltammetry (CV) was conducted at a scan rate of $50 \mathrm{mV} \mathrm{s}^{-1}$ to obtain the electrochemical active area of samples by computing the $\mathrm{H}_{2}$ desorption peak of the CV curve. The ORR polarization curves were obtained at $1600 \mathrm{rpm}$ with a sweep rate of $10 \mathrm{mV} \mathrm{s}^{-1}$ in $\mathrm{O}_{2}$-saturated $0.1 \mathrm{M}$ $\mathrm{HClO}_{4}$ solution. The accelerated durability tests (ADT) were performed in oxygen-saturated $0.1 \mathrm{M} \mathrm{HClO}_{4}$ solutions by potential cycling between 0.6 and $1.1 \mathrm{~V}$ versus RHE under a scan rate of $100 \mathrm{mV} \mathrm{s}^{-1}$ for 10,000 cycles. To study the ORR mechanism, the Pt loading was maintained, while the rotating ring-disk electrode (RRDE) measurements were performed and the ring current was collected with the potential fixed at $1.4 \mathrm{~V}$ versus RHE. The $n$ was calculated according to the equation [22,23]:

$$
n=4 \times \frac{I_{D}}{I_{D}+I_{R} \div N}
$$

Where $I_{\mathrm{D}}$ and $I_{\mathrm{R}}$ represent the disk and ring current, respectively. $N(0.37)$ is the current collection efficiency of the Pt ring.
For MOR, the CV curves were recorded at a sweep rate of 50 $\mathrm{mV} \mathrm{s}^{-1}$ in $\mathrm{N}_{2}$-saturated $0.5-\mathrm{M} \mathrm{H}_{2} \mathrm{SO}_{4}$ solution. The MOR curves were recorded (-0.2-1.0 V vs. SCE) under a scan rate of $50 \mathrm{mV}$ $\mathrm{s}^{-1}$ in a solution of $0.5 \mathrm{M} \mathrm{H}_{2} \mathrm{SO}_{4}$ and $1.0 \mathrm{M} \mathrm{CH}_{3} \mathrm{OH}$. In terms of the CO-stripping measurements, the working electrode was first held at $-0.14 \mathrm{~V}$ vs. SCE for absorption of $\mathrm{CO}$ and the $\mathrm{CV}$ curves were then recorded in $0.5-\mathrm{M} \mathrm{H}_{2} \mathrm{SO}_{4}$ solution with a sweep rate of $50 \mathrm{mV} \mathrm{s}^{-1}$. All electrochemical experiments were performed at $25^{\circ} \mathrm{C}$.

\section{Results and discussion}

\subsection{Synthesis and structural characteristics}

Pt-Ni HSNs were prepared by a solvothermal method, entailing two key steps: firstly, chloroplatinic acid $\left(\mathrm{H}_{2} \mathrm{PtCl}_{6} \cdot 6 \mathrm{H}_{2} \mathrm{O}\right)$, nickel(II) acetate $\left[\mathrm{Ni}\left(\mathrm{CH}_{3} \mathrm{COO}\right)_{2}\right]$ (as metal precursor), cetyltrimethylammonium chloride (CTAC, serves as stabilizer reagent), and $\mathrm{H}_{2} \mathrm{SO}_{4}$ (as a structure-growing reagent) were all mixture together in the reducing medium of oleylamine (OAM) to form the Pt-Ni bimetallic nanocomposite intermediates. Secondly, the intermediates were treated with acetic acid to remove any unstable $\mathrm{Ni}$ species, resulting in the final Pt-Ni HSNs. In Figs. 1(a)-(e), the SEM and TEM images illustrate the morphologies of the Pt-Ni bimetallic intermediates synthesized in the first step. They exhibit a uniform octahedral shape with a narrow particle size distribution (Figs. S1(a) and (d)) and an average particle size of $79.8 \mathrm{~nm}$ (Fig. 1(a)). The HAADF-STEM image further displays numerous small particles grown on the outer layer of the octahedral core (Figs. S1(b) and (e)). The size of the satellite particles is approximately $7.12 \mathrm{~nm}$. The inset in Fig. 1(b) reveals that the element ratio of $\mathrm{Ni}$ is higher than Pt in the intermediates. Figs. 1(c) and (d) illustrate highly crystalline features, and the d-spacing between adjacent lattice fringes are $0.191 \mathrm{~nm}$ (or $0193 \mathrm{~nm}$ ) and $0.233 \mathrm{~nm}$, corresponding to the (200) and (111) crystal planes of Pt, respectively. Fig. 1(e) depicts the scanning transmission electron microscopy (STEM)
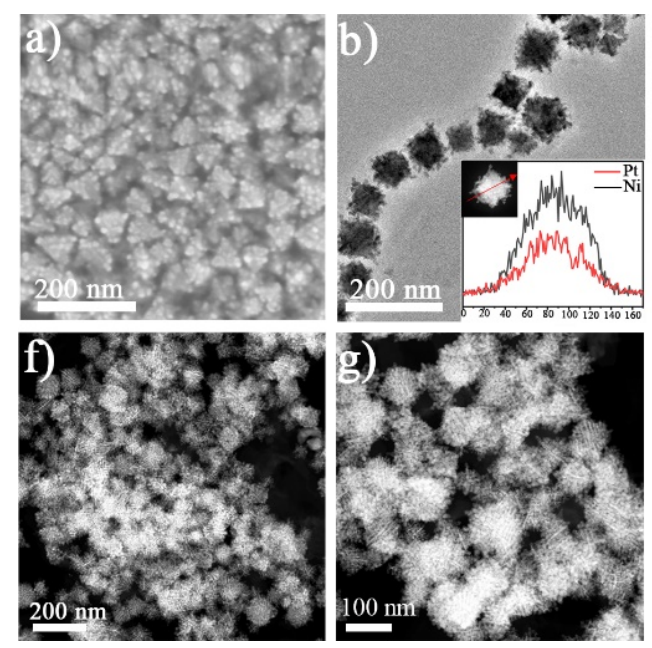
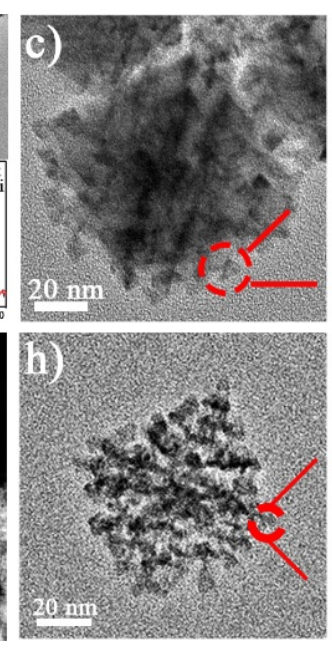
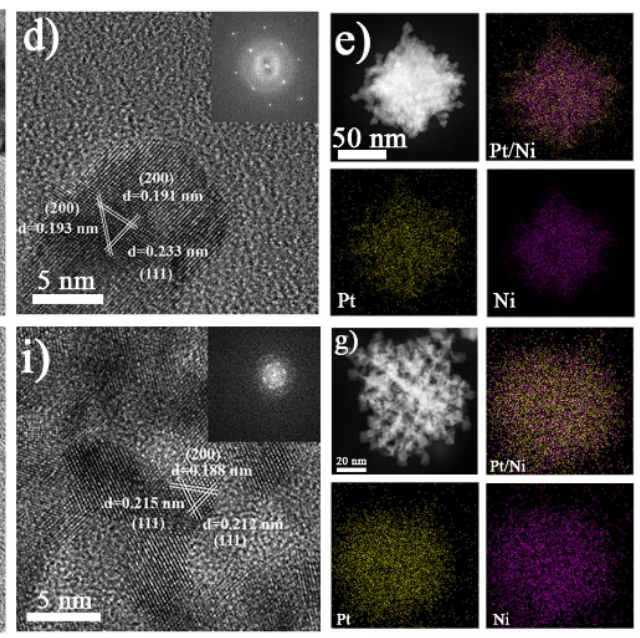

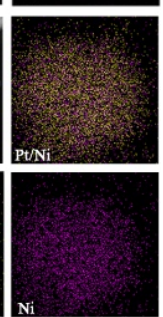

Fig. 1. Pt-Ni bimetallic nanocomposites synthesized with the inclusion of $\mathrm{H}_{2} \mathrm{SO}_{4}$ in the first step: (a) SEM image, (b) low-resolution TEM images and line profile analysis, (c,d) high-magnification TEM image and (e) HAADF-STEM image with elemental mapping of a single particle. Hierarchically skeletal Pt-Ni nanocrystals (HSNs) after acid-leaching treatment: (f,g) STEM image, (h,i) high-resolution TEM images and (g) the HAADF-STEM image with EDS mapping images of a single Pt-Ni HSN. 
image and the corresponding elemental distribution of Pt and Ni obtained by a high-angle annular dark-field scanning transmission electron microscope equipped with an energy-dispersive spectrometer (HAADF-STEM-EDS); it can be clearly seen that $\mathrm{Pt}$ is uniformly distributed throughout the entire area, while Ni is predominantly located in the core. The atomic ratio of $\mathrm{Pt}$ and $\mathrm{Ni}$ is 33:67. Following the acid-leaching treatment of Pt-Ni intermediates, their final fine structure is shown in Figs. 1(f)-(i). As shown in Fig. S1(c) and (f), the Pt-Ni HSNs possess a hierarchically skeletal structure with a mean size of $79.0 \mathrm{~nm}$, which is exposed to a multitude of holes. From Figs. 1(f), (g), and (h), it is evident that the Pt-Ni HSNs were assembled from numerous hierarchically skeletal grains, and that abundant voids exist inside the catalyst, which are expected to contribute positively to enhancing the performance of the catalyst. To further elucidate the detailed structure of the obtained nanocrystals, high-resolution TEM (HRTEM) images of individual Pt-Ni HSNs were obtained, as shown Figs. 1(h) and (i). The FFT pattern implies the polycrystalline nature of Pt-Ni HSNs [24]. The lattice spacings at the branched region are shown to be 0.188 and $0.215 \mathrm{~nm}$ (or $0.212 \mathrm{~nm}$ ), corresponding to the (200) and (111) crystal planes of a face-centered cubic (fcc) lattice, respectively, which is present in Pt [25]. The $\{200\}$ lattice distance is revealed to be $0.188 \mathrm{~nm}$, implying a Pt atomic composition of 57\% according to Vegard's law [15]. The \{200\} crystal lattice spacings of Pt and $\mathrm{Ni}$ are 0.197 and $0.176 \mathrm{~nm}$, respectively, which is in good agreement with the inductively coupled plasma atomic emission spectroscopy (ICP-AES) results. Furthermore, The EDS mapping images (Fig. 1(g)) indicate that the Pt and $\mathrm{Ni}$ are uniformly mixed in throughout the nanocrystal.

Coincidentally, when $1 \mathrm{M}$ sulfuric acid was not added to the reaction, Pt-Ni multi-branched catalysts were obtained instead of the HSNs. Numerous dendrimers were present on the surface of this structure, which can improve the utilization of Pt. The TEM image (Fig. 2(a)) shows the uniform morphology and high yield of the catalyst [21]. Fig. 2(b) clearly displays that a single Pt-Ni MB consists of a core and a dense outer branch. EDS mapping images (Fig. 2(c)) indicate that the inner shell of the catalyst is chiefly composed of $\mathrm{Ni}$, while $\mathrm{Pt}$ is present throughout the entire catalyst and is concentrated in the outer portion. The structural features of the catalyst were characterized in detail (Figs. 2(d) and (e)). The lattice spacing of 0.188 (or $0.187 \mathrm{~nm}$ ) and $0.132 \mathrm{~nm}$ on the branch correspond to the (200) and (220) crystal planes of the Pt-Ni alloy, respectively. The formation of the Pt-Ni alloy was confirmed. Energy dispersive X-ray spectroscopy (EDS) results are represented in Fig. 2(f), indicating a Pt:Ni atomic ratio of 56:44, which agrees with the ICP-AES data. Therefore, we can confirm the successful synthesis of the Pt-Ni alloy. Moreover, it was confirmed that the $\mathrm{Ni}$ is not fully reduced from the precursor, as it is possibly being partially hydrolyzed. Overall, the results verified that sulfuric acid exerts a significant effect on the morphology of the Pt-Ni catalyst.

To explore the Pt-Ni HSN formation process in detail, intermediate structures were analyzed at different times during the reaction. The formation mechanism of Pt-Ni HSNs can be illustrated by the STEM images. In the initial stage of the reaction at 5 h (Fig. 3(a)), scaffold-like Pt-Ni nanostructures were formed by the rapid reduction and deposition of small $\mathrm{Pt}$ and Ni nuclei at $160^{\circ} \mathrm{C}$, and EDS analysis indicated that atomic compositions of Pt and $\mathrm{Ni}$ in the scaffold-like Pt-Ni nanocrystals was $49 \%$ and 51\%, respectively (Fig. S2(a)). As shown in Fig. S3, the XRD peak pattern at $5 \mathrm{~h}$ suggested the presence of intermediates between the Pt and Ni reflections, indicating the formation of Pt-Ni alloy phases. The Ni (II) was reduced before Pt (IV) under the same conditions, although the standard redox potential for $\mathrm{PtCl}_{6}{ }^{2-} / \mathrm{Pt}\left(0.74 \mathrm{~V}\right.$ vs. RHE) is more positive than that of $\mathrm{Ni}^{2+} / \mathrm{Ni}$ $(-0.25 \mathrm{~V}$ vs. RHE). A possible reason is that the two precursors and CTAC dissolve in OAM via electrostatic attraction and the chelate effect, which would weaken the contact between $\mathrm{H}_{2} \mathrm{PtCl}_{6}$ and OAM (as the reducing agent) and reduce the decomposition rate of $\mathrm{H}_{2} \mathrm{PtCl}_{6}$ [26-28]. Therefore, $\mathrm{Ni}^{2+}$ was reduced more readily and led to the formation of scaffold-like
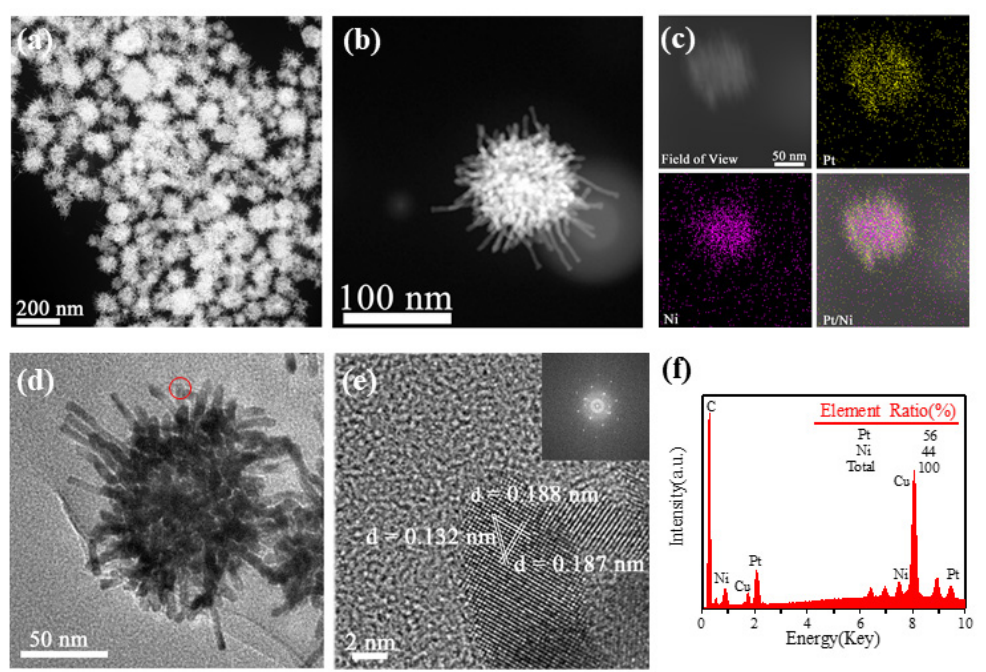

Fig. 2. Multi-branched Pt-Ni catalyst synthesized without $\mathrm{H}_{2} \mathrm{SO}_{4}$ : (a,b) the HAADF-STEM image of the (MBs) and (c) EDS mapping images. (d) Bright-field TEM image of an individual Pt-Ni MB; (e) the corresponding local HR-TEM image. The inset shows the corresponding FFT pattern. (f) The EDS spectra and atomic compositions of Pt-Ni MBs. 


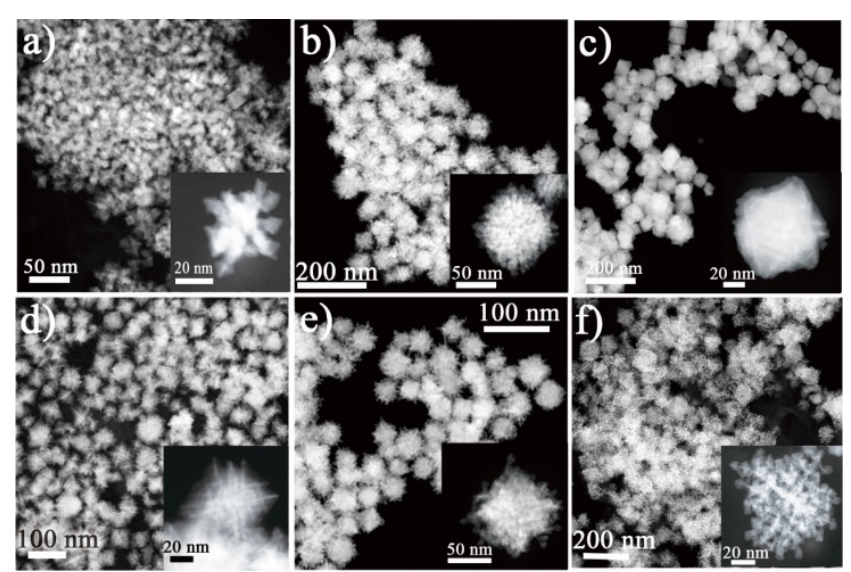

Fig. 3. HAADF-STEM images of Pt-Ni HSNs obtained at 5 (a), 8 (b), 12 (c), 16 (d), and 20 (e) h and after the chemical etching process (f). The insets depict high magnification images of the corresponding individual Pt-Ni nanostructure.

Pt-Ni alloys in the early stages of the reaction.

When the reaction time was increased to $8 \mathrm{~h}$, it was found that numerous small scaffold-like Pt-Ni nanocrystals aggregate to form a larger octahedral-like dendrite. Furthermore, copious small particles were observed to be distributed on the surface of the dendrite. The TEM images (Fig. 3(b)) illustrate the self-assembly process of primary nanocrystals.

There have been reports that l-lysine, arginine, or glutamic acid can facilitate the process of self-assembly [9,26,29]. Sulfuric acid ( $1 \mathrm{M}$ ) could be responsible for the growth by self-assembly observed in our study. The atomic composition ratio of Pt and $\mathrm{Ni}$ in the Pt-Ni HSNs at $8 \mathrm{~h}$ was 52:48, as obtained by EDS analysis (Fig. S2(b)). Notably, the Pt and Ni content did not differ significantly from that observed at $5 \mathrm{~h}$. The XRD pattern likewise revealed the presence of a Pt-Ni alloy. In this process, $\mathrm{H}_{2} \mathrm{SO}_{4}$ acts as the directing agent, and the metal precursors are continuously reduced under the action of the reducing agent.

Upon further increase of the reaction time to $12 \mathrm{~h}$, more $\mathrm{Ni}$ was reduced to fill the space among the dendrite branches. As shown in Fig. 3(c), a Pt-Ni solid-octahedron formed due to the constant deposition of $\mathrm{Ni}$ on the Pt-Ni dendrites. According to EDS analysis (Fig. S2(c)), the atomic ratio of Ni increases to $62 \%$ from $48 \%$; moreover, the evident peak in the XRD pattern (Fig. S3(c)) corresponds to the $\{111\}$ diffractions of the Pt-Ni and Ni phase. When the reaction time was extended to $16 \mathrm{~h}$, the HAADF-STEM image, presented in Fig. 3(d), exhibited vivid bright lines along the inner axes and several edges of the octahedron, although other irregular shapes were observed. The atomic compositions of $\mathrm{Pt}$ and Ni were $36 \%$ and $64 \%$, respectively, as obtained by EDS measurement (Fig. S2(d)). The Ni content increased slightly with prolonged reaction time. The $\{111\}$ diffractions peaks in the XRD pattern indicate two distinct groups that are indexed to the Pt-Ni alloy, and the $\mathrm{Ni}$ phase, thus, the octahedral Pt-Ni intermediate was generated with phase-segregation at this stage $[27,30]$.

As the reaction time was prolonged to $20 \mathrm{~h}$, the remaining $\mathrm{Ni}$ and Pt were reduced simultaneously in the reactant because the Ni quantity was lower. The remaining precursor in the so- lution formed abundant granular Pt-Ni alloy under the action of the reducing agent; subsequently, growth via self-assembly occurred on the octahedral surface in a weakly acidic environment. Finally, Pt-Ni bimetallic nanocomposites were synthesized. The respective atomic compositions of $\mathrm{Pt}$ and $\mathrm{Ni}$ in the intermediate were $33 \%$ and $67 \%$, respectively, as determined by EDS analysis (Fig. S2(e)). The HAADF-STEM images are shown in Fig. 3(e) and Fig. 1. The alloy structure was confirmed by XRD analysis (Fig. S3(e)). Therefore, we could conclude the successful fabrication of Pt-Ni HSNs by acid etching. A number of unstable elements were eliminated with etching, which is beneficial for the stability of the particles. Fig. 3(f) indicates that Pt-Ni HSNs possess a skeletal structure, while the interior is mostly hollow. This porous architecture permits the exposure of a larger surface area, which significantly increases the atomic utilization of the precious metal. Ultimately, the activity and durability of the catalyst are expected to increase. A detailed description is presented in the introduction.

Based on the above analysis pertaining to reaction times and previous reports $[9,31,32]$, we proposed a possible mechanism for the synthesis of Pt-Ni HSNs. As shown in Scheme 1, at the initial stage, the precursors are dissolved in the mixed solution of OAM and CTAC in an acidic environment, which prevents the hydrolysis of Ni salts. Although the standard reduction potential of the $\mathrm{PtCl}_{6}{ }^{2-} / \mathrm{Pt}(0.74 \mathrm{~V}$ vs. RHE) pair is higher than that of the $\mathrm{Ni}^{2+} / \mathrm{Ni}(-0.25 \mathrm{~V}$ vs. RHE) couple, owing to the effect of CTAC and several Pt(IV) species arising from aqua and hydroxy substitution for the $\mathrm{PtCl}_{6}{ }^{2-}$ complex in aqueous solution [33], the Ni precursors will preferentially be reduced over Pt precursors at high temperatures. The generated $\mathrm{Pt}$ and $\mathrm{Ni}$ atoms could undergo oriented attachment, predominantly driven by the strong interactions with CTAC and $\mathrm{H}_{2} \mathrm{SO}_{4}$, to reduce the total surface energy of the system, generating scaffold-like Pt-Ni alloys. Meanwhile, the primary scaffold-like Pt-Ni alloys coalesce by oriented attachment, crystal growth, and self-assembly to form octahedral dendrites. To a certain extent, the $\mathrm{Ni}$ atoms are more abundant than $\mathrm{Pt}$ atoms in the solution at that time. The excessive $\mathrm{Ni}$ atoms are deposited on the octahedral dendrites, leading to the formation of a Pt-Ni solid-octahedron. In the synthetic process, $\mathrm{H}_{2} \mathrm{SO}_{4}$ plays a critical guiding role in controlling the morphology of the nanoparticles; owing to the selective capping of $\mathrm{H}_{2} \mathrm{SO}_{4}$ on the facets, $\mathrm{Pt}$ and $\mathrm{Ni}$ atoms tend to be deposited on the (111) facet, thereby promoting the Pt-Ni alloy growth into an octahedral structure along the $<111>$ direction. Ultimately, Pt-Ni HSNs were con-

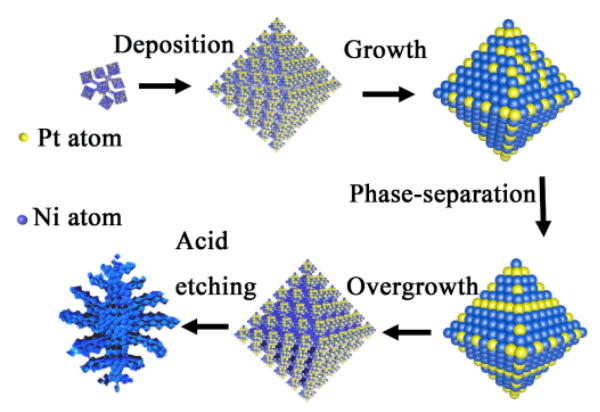

Scheme 1. The growth mechanism of Pt-Ni HSNs. 
structed by the acid etching process.

To further explore the physical characteristics of Pt-Ni HSNs and Pt-Ni MBs, we conducted XRD and XPS analyses. From the XRD patterns presented in Fig. 4(a), it is evident that four distinctive diffraction peaks exist for each sample, which correspond to the (111), (200), (220), and (311) diffraction planes of Pt (face centered-cubic (fcc) crystal structure) [34,35]. It is evident that the four peaks of the Pt-Ni HSNs catalysts and Pt-Ni MBs have a slight right shift towards a higher angle, compared with those of commercial $\mathrm{Pt} / \mathrm{C}$, indicating the formation of well-alloyed Pt-Ni structures with a reduced lattice distance [36,37]. Thus, the Pt-Ni alloy not only improved electrocatalytic activity, but additionally enhanced stability. This is chiefly due to the alteration of the electronic structure of $\mathrm{Pt}$, and the reduction of the d-banding center [38]. Meanwhile, no impurity peaks were observed in the XRD patterns, indicating a single-phase alloy in the sample. The surface compositions and single elemental state of the catalysts were determined by X-ray photoelectron spectroscopy (XPS). As shown in Fig. S4, the four major peaks of Pt-Ni HSNs correspond to the four elements, $\mathrm{Pt}, \mathrm{C}, \mathrm{O}$, and $\mathrm{Ni}$, and their binding energies were 71.6, $284.8,532.4$, and $855.9 \mathrm{eV}$, respectively. This additionally confirms the presence of all four elements as constituents of the catalyst. However, only three major peaks were present in the XPS spectrum of TTK-Pt/C. It was thus confirmed that the catalyst absorbed oxygen from the environment. In addition, we obtained the atomic ratio of $\mathrm{Pt}$ to $\mathrm{Ni}$ as 1.93:1.65 on the surface of Pt-Ni HSNs from the XPS spectra shown in Fig. 4(b), which is in close agreement with the results obtained by EDS analysis. The atomic ratio of $\mathrm{Pt} / \mathrm{Ni}$ was determined to be $1.33: 1$ by inductively coupled plasma mass spectrometry (ICP-MS). This confirms that the distribution of $\mathrm{Pt}$ and $\mathrm{Ni}$ is relatively uniform throughout the entire particle. The Pt exhibits two intense peaks at 71.67 and $75.04 \mathrm{eV}$, which correspond to $\mathrm{Pt} 4 f_{7 / 2}$ and Pt $4 f_{5 / 2}$ of Pt (0), respectively. Two additional weaker peaks were observed with bond energies of 72.71 and $77.28 \mathrm{eV}$, respectively, indicating the presence of Pt oxides on the catalyst surface $[39,40]$. The atomic contents, calculated based on the areas of the corresponding peaks in the Pt $4 \mathrm{f}$, were $28.8 \%$, $18.2 \%, 36.1 \%$, and $16.9 \%$, respectively, indicating that the majority of the Pt species in the Pt-Ni HSNs was of the Pt (0) type. Furthermore, in Fig. 4(b), it is evident that the $4 f_{7 / 2}$ peak of the Pt-Ni HSNs catalyst is blue-shifted compared with the $4 f$ position of pure Pt (71.32 eV for Pt $4 f_{7 / 2}$ and $74.79 \mathrm{eV}$ for Pt $4 f_{5 / 2}$ ), indicating that the Pt-Ni alloying structure had formed, thereby downshifting the Pt d-band center [36,39-41]. This shift contributes to lattice strain and charge transfer by $\mathrm{Ni}$ alloying, consequently increasing catalytic intrinsic activity [6]. It is evident from Fig. 4(c) that the intensity of metallic Ni is greater than that of the oxidized state of $\mathrm{Ni}$, indicating that the majority of the Ni exists with zero valence. The lack of oxidized species may be due to the removal of surface Ni during acid treatment [42]. Similarly, XPS characterization for Pt-Ni MBs was performed, as shown in Fig. 4(b) and (c). The Pt-Ni MBs catalyst exhibits the blue-shift compared with the $4 \mathrm{f}$ position of pure $\mathrm{Pt}$, verifying that the surface of Pt-Ni MBs is in an alloy state. The chemical composition and XPS results of the various catalysts are summarized in the Table S1.

The optimization of parameters for the generation of the Pt-Ni bimetallic nanocomposites, pivotal in the synthesis of Pt-Ni HSNs, was further investigated by a series of experiments. Firstly, we increased the amount of CTAC from 150 to $200 \mathrm{mg}$; a number of octahedral particles doping other irregular shapes were observed, and as seen in Fig. S5(a). Porous nanoparticles were formed in the absence of CTAC (Fig. S5(b)). When CTAB was added instead of CTAC, the formation of nanoparticles with long branches on their surface was observed (Fig. S5(c)). Next, we investigated the effect of the Ni-precursor on the morphology of the produced catalysts. Substituting $\mathrm{Ni}\left(\mathrm{CH}_{3} \mathrm{COO}\right)_{2}$ with the same molar amount of $\mathrm{NiCl}_{2} \cdot 6 \mathrm{H}_{2} \mathrm{O}$ or $\mathrm{Ni}\left(\mathrm{NO}_{3}\right)_{2} \cdot 6 \mathrm{H}_{2} \mathrm{O}$ led to a significant increase in particle size, along with the loss of octahedral geometry and a rough surface appearance (Fig. S5(d), (e)). From the results regarding the above two precursors of $\mathrm{Ni}$, we can conclude that the Pt-Ni bimetallic nanocomposites can be formed under weakly acidic ionic conditions. When $\mathrm{H}_{2} \mathrm{PtCl}_{6} \cdot 6 \mathrm{H}_{2} \mathrm{O}$ was replaced with $\mathrm{Pt}(\mathrm{acac})_{2}$, nodular nanocrystals were produced (Fig. S5(f)). When a strong reducing agent (DMF) was added to the reaction instead of OAM, a multitude of irregular particles with a size of approximately $20 \mathrm{~nm}$ were obtained, as shown in Fig. S5(g). Excluding $\mathrm{H}_{2} \mathrm{SO}_{4}$, while keeping the other conditions constant, resulted in multi-branched Pt-Ni catalysts (Fig. S5(h)). From the results displayed in Fig. $\mathrm{S} 5$, the following conclusions can be drawn: the $\mathrm{H}_{2} \mathrm{SO}_{4}$ acts as a director, determining the morphology of the Pt-Ni bimetallic nanocomposites, and an appropriate amount of CTAC can promote stable crystal growth along the (111) crystal plane [43]. As previously mentioned, the acidic environment induces the formation of a self-assembled structure $[44,45]$. The addition of sulfuric acid is therefore a key factor for the optimal synthesis of the structure. The influence of reaction temperature was investigated, and results corresponding to synthesis temperatures of 160 to 170 and $180{ }^{\circ} \mathrm{C}$, were obtained. Both micrographs in Figs. S5(i) and (j) indicate the formation of a smaller core/satellite-like structure, compared to Pt-Ni bime-
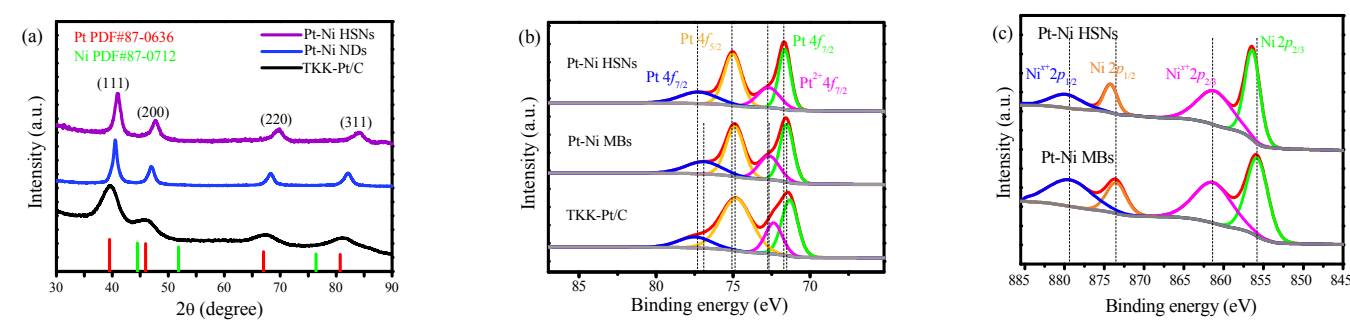

Fig. 4. (a) XRD patterns of Pt-Ni HSNs, Pt-Ni MBs, and commercial Pt/C; The corresponding XPS spectra of Pt $4 f$ (b) and Ni $2 p$ (c). 
tallic nanocomposites. The reason for this morphology is that the high temperature accelerates the rate of reduction in the reactant solution. Therefore, the metal atoms rapidly deposit to form a solid inner shell and the concentration of the reactants gradually decreases, causing the remaining metal ions to be reduced to small particles under the action of acidic ions and deposited on the surface of the inner shell to form a core/satellite-like structure. In short, the use of $\mathrm{H}_{2} \mathrm{PtCl}_{6} \cdot 6 \mathrm{H}_{2} \mathrm{O}$ and $\mathrm{Ni}\left(\mathrm{CH}_{3} \mathrm{COO}\right)_{2} \cdot 4 \mathrm{H}_{2} \mathrm{O}$ as precursors, an appropriate amount of CTAC as a stabilizer, OAM as a reducing agent and solvent, and $\mathrm{H}_{2} \mathrm{SO}_{4}$ as directing agent at $160{ }^{\circ} \mathrm{C}$, represent optimal conditions for the obtainment of the Pt-Ni bimetallic nanocomposites.

\subsection{Electrochemical activity for ORR and MOR}

The ORR activity of the catalysts was determined in $0.1 \mathrm{M}$ $\mathrm{HClO}_{4}$ in a three-electrode system. As show in Fig. 5(a), the cyclic voltammogram characteristic curves of Pt-Ni HSNs, Pt-Ni MBs and Pt/C catalysts were recorded in $0.1 \mathrm{M} \mathrm{HClO}_{4}$ aqueous solution saturated with nitrogen at a potential sweep of $50 \mathrm{mV}$ $\mathrm{s}^{-1}$. The ECSAs, calculated by integrating the hydrogen adsorption area, were $44.5 \mathrm{~m}^{2} \mathrm{gpt}^{-1}$ for Pt-Ni HSNs, $30.5 \mathrm{~m}^{2} \mathrm{gpt}^{-1}$ for Pt-Ni MBs and $42.7 \mathrm{~m}^{2} \mathrm{gpt}^{-1}$ for the commercial Pt/C. It should be noted that ECSA of HSNs is considerably higher than that of MBs and approaches that of Pt nanoparticles on carbon (Pt/C), indicating that HSNs possess an extensive active surface area available for electrochemical reactions, which would result in enhanced electrochemical activity. Fig. 5(b) depicts ORR LSV curves of Pt-Ni HSNs, Pt-Ni MBs and state-of-the-art Pt/C, acquired in $\mathrm{O}_{2}$-saturated $0.1 \mathrm{M} \mathrm{HClO}_{4}$ solutions at a potential sweep of $10 \mathrm{mV} \mathrm{s}^{-1}$. The half-wave potential (defined as $3.0 \mathrm{~mA}$ $\mathrm{cm}^{-2}$ ) of Pt-Ni HSNs is $0.930 \mathrm{~V}$, which is superior to that of Pt-Ni MBs (0.917 V) and that of commercial Pt/C (0.87 V), indicating that Pt-Ni HSNs possess an outstanding ORR activity [46]. Moreover, the high ORR activity of the HSNs was additionally inferred by the mass activity (MA) at $0.9 \mathrm{~V}$ vs. RHE. As shown in Fig. 5(c), the MA of Pt-Ni HSNs is $1.25 \mathrm{~A} \mathrm{~m}^{2} \mathrm{gpt}^{-1}$, which is 1.9 times higher than that of Pt-Ni MBs $\left(0.65 \mathrm{~A} \mathrm{~m}^{2} \mathrm{gpt}^{-1}\right)$, and 8.9 times higher than that observed for commercial Pt/C (0.14 A $\left.\mathrm{m}^{2} \mathrm{gpt}^{-1}\right)$. In reference to the activity of Pt-Ni HSNs, we generated a normalized graph for comparison (Fig. 5(d)), where it is evident that the mass activities of commercial Pt/C and Pt-Ni MBs are $11.2 \%$ and $52 \%$ that of Pt-Ni HSNs, respectively. Catalyst stability is another critical factor for evaluating feasibility for practical applications. To assess the stability of the catalyst, an accelerated ORR durability test (ADT) was performed between 0.6 and $1.1 \mathrm{~V}$ at a sweep rate of $100 \mathrm{mV} \mathrm{s}^{-1}$ in $\mathrm{O}_{2}$-saturated $0.1 \mathrm{M} \mathrm{HClO}_{4}$ solution for 10,000 cycles. The LSV curves of the Pt-Ni HSNs and Pt/C catalysts before and after 10000 cycles toward ORR are shown in Fig. 5(e). The half-wave potential of Pt-Ni HSNs became $0.920 \mathrm{~V}$ after 10000 cycles, which is a negative shift of merely $10 \mathrm{mV}$. On the other hand, the half-wave potential of TKK-Pt/C decreased to $0.801 \mathrm{~V}$. By comparing the mass activity values after 10000 cycles (Fig. 5(f)), Pt-Ni HSNs exhibit 21.6\% loss, while Pt/C catalyst activity is reduced by $50 \%$, implying that HSNs have a higher endurance under harsh working conditions. This is due to the fact that Pt-Ni HSNs exhibit a minor structural collapse after 10000 cycles, while the TKK-Pt/C catalyst displays drastic agglomeration, which significantly weakens the stability. To study the catalytic kinetics of Pt-Ni HSNs, we derived the Tafel plots from the polarization curves of the synthesized catalysts [47]. As shown in Fig. 6(a), the Pt-Ni HSNs produced a markedly lower
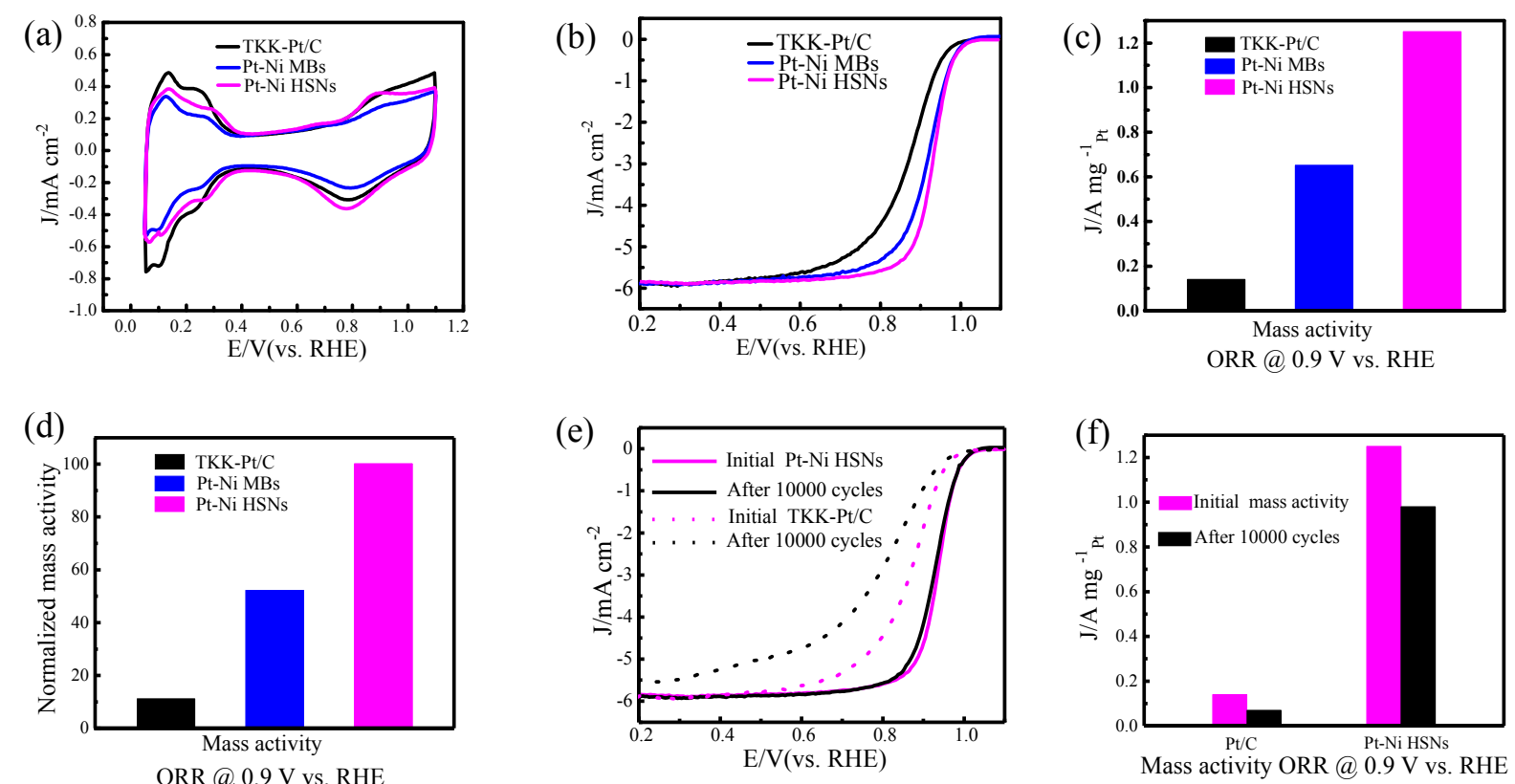

Fig. 5. Electrochemical properties of the Pt-Ni HSNs/C catalyst, Pt-Ni MBs and commercial Pt/C catalyst toward ORR. (a) CV curves in $\mathrm{N}_{2}$-saturated electrolyte at $50 \mathrm{mV} \mathrm{s}^{-1}$; (b) LSV recorded at $10 \mathrm{mV} \mathrm{s}^{-1}$ and $1600 \mathrm{rpm}$; (c) Mass activity comparison at $0.9 \mathrm{~V}$ versus RHE; (d) Normalized mass activity; (e) ORR polarization curves of the Pt-Ni HSNs and the TKK-Pt/C before and after scanning 10,000 cycles in $0.1 \mathrm{M} \mathrm{HClO}_{4}$ aqueous solution; (f) Performance comparison with $\mathrm{Pt} / \mathrm{C}$. 

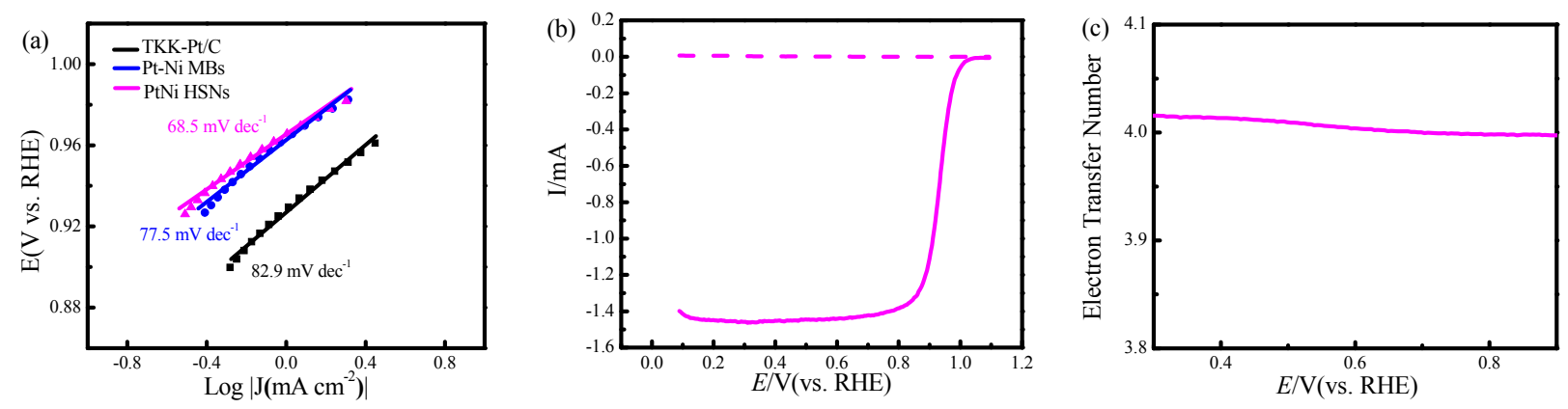

Fig. 6. (a) Tafel plots for the Pt-Ni HSNs/C catalyst, Pt-Ni MBs and commercial Pt/C catalyst; (b) the curve for the RRDE test; (c) the curve of electron transfer number of the Pt-Ni HSNs/C catalyst.

Tafel slope (68.5 $\mathrm{mV} \mathrm{dec}^{-1}$ ) compared to Pt-Ni MBs (77.5) and TKK-Pt/C (82.9), which implies that the transfer of the first electron on the active sites of the catalyst is the crucial step $[48,49]$. To further explain the excellent performance of Pt-Ni HSNs, the transferred electron number, obtained through RRDE measurements (Figs. 6(b) and (c)), approaches 4 for Pt-Ni HSNs, confirming a rapid $4 \mathrm{e}^{-}$pathway for ORR.

Furthermore, Pt-Ni HSNs display a significantly higher activity towards methanol oxidation compared to commercial Pt/C. Fig. 7(a) illustrates the CV curves of the three catalysts obtained at a sweep rate of $50 \mathrm{mV} \mathrm{s}^{-1}$. The Pt-Ni HSNs have the highest anodic oxidation peak density, significantly higher than that of Pt-Ni MBs and Pt/C. The mass activities of the Pt-Ni HSNs and the Pt-Ni MBs at the peak current were $2.17 \mathrm{~A} \mathrm{mgpt}^{-1}$ and $1.51 \mathrm{~A} \mathrm{mg}^{-1}$, which is 4.2 and 2.9 times higher than that of the commercial $\mathrm{Pt} / \mathrm{C}$ catalyst $\left(0.52 \mathrm{~A} \mathrm{mgpt}^{-1}\right)$, respectively, as shown in Fig. 7(b). CO stripping experiments further revealed the origin of enhanced HSNs MOR activity. As shown in Fig. 7(c), the Pt-Ni HSNs have a lower CO oxidation overpotential, indicating a higher $\mathrm{CO}$ tolerance compared to commercial $\mathrm{Pt} / \mathrm{C}$. Table S2 compares the electrochemical performance of the Pt-Ni alloy with previously reported catalysts. Generally, Pt-Ni HSNs display good activity in ORR and MOR. Two points are ascribed to the excellent activity of HSNs: firstly, the Pt-Ni HSNs are assembled from a plurality of small alloy particles, which greatly improves the contact area with the electrolyte; secondly, the unique skeletal structure reduces the possibility of agglomeration between the particles and enhances mass trans- portation.

\section{Conclusions}

In summary, we have successfully synthesized a novel type of hierarchically skeletal Pt-Ni nanocrystals (HSNs) with a multi-layered structure, via an $\mathrm{H}_{2} \mathrm{SO}_{4}$-induced solvothermal method. A series of comparative tests demonstrated that the sulfuric acid is critical for optimal structure formation. The Pt-Ni HSNs catalysts exhibit enhanced activity and stability compared to the commercial Pt/C for ORR, due to their highly stable open structure and large specific surface area of the Pt $\{111\}$ facet. Additionally, the HSNs show enhanced activity and tolerance in CO for MOR. This discovery provides a new approach for the design of advanced Pt based electrocatalysts, which entails the induction of a self-assembly process.

\section{References}

[1] L. Bu, S. Guo, X. Zhang, X. Shen, D. Su, G. Lu, X. Zhu, J. Yao, J. Guo, X. Huang, Nat. Commun., 2016, 7, 11850.

[2] L. Cao, W. Liu, Q. Luo, R. Yin, B. Wang, J. Weissenrieder, M. Soldemo, H. Yan, Y. Lin, Z. Sun, C. Ma, W. Zhang, S. Chen, H. Wang, Q. Guan, T. Yao, S. Wei, J. Yang, J. Lu, Nature, 2019, 565, 631-635.

[3] I.-A. Choi, D.-H. Kwak, S.-B. Han, J.-Y. Park, H.-S. Park, K.-B. Ma, D.-H. Kim, J.-E. Won, K.-W. Park, Appl. Catal. B, 2017, 211, 235-244.

[4] J. Park, M. Kanti Kabiraz, H. Kwon, S. Park, H. Baik, S.-I. Choi, K. Lee, ACS Nano, 2017, 11, 10844-10851.
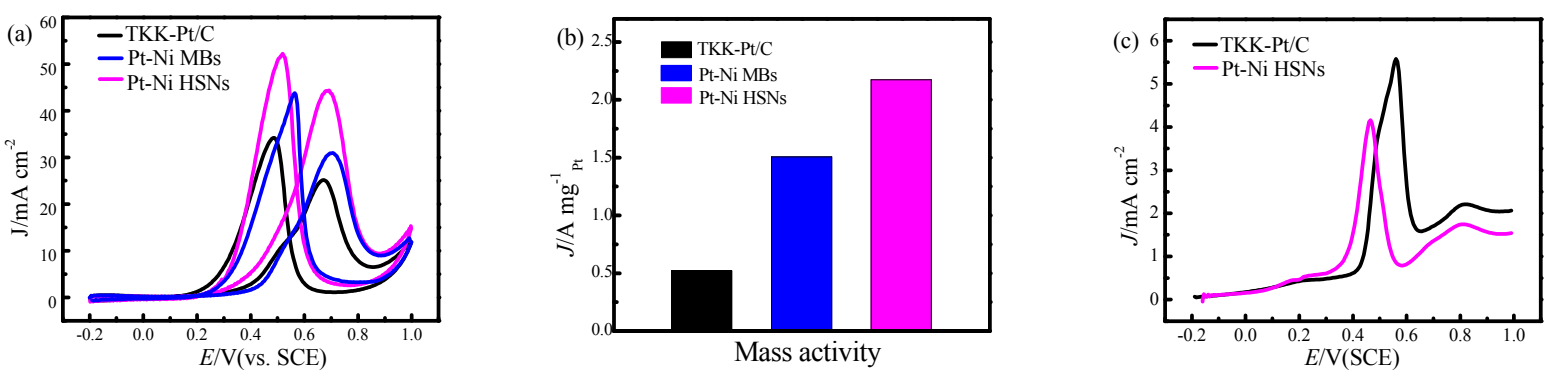

Fig. 7. Electrochemical performances of the as-prepared Pt-Ni HSNs, Pt-Ni MBs and commercial Pt/C catalysts toward MOR. (a) CV curves in 0.5-M $\mathrm{H}_{2} \mathrm{SO}_{4}+1.0-\mathrm{M} \mathrm{CH} 3 \mathrm{OH}$ aqueous solution; (b) Mass activity of the three catalysts at the peak potential; (c) CO stripping voltammograms of the three catalysts in $0.5 \mathrm{M} \mathrm{H}_{2} \mathrm{SO}_{4}$. 


\section{Graphical Abstract}

Chin. J. Catal., 2021, 42: 648-657 doi: 10.1016/S1872-2067(20)63680-4

Hierarchically skeletal multi-layered Pt-Ni nanocrystals for highly efficient oxygen reduction and methanol oxidation reactions

Shibo Li, Zhi Qun Tian, Yang Liu, Zheng Jang, Syed Waqar Hasan,

Xingfa Chen, Panagiotis Tsiakaras*, Pei Kang Shen *

Guangxi University, China;

Institute of High Temperature Electrochemistry, Russia;

Ural Federal University, Russia; University of Thessaly, Greece

The Pt-Ni catalyst presents a hierarchically skeletal nanostructure upon etching, which provides a large specific surface area of the Pt $\{111\}$ facet. The well-defined self-supported structure exhibits enhanced activity towards ORR and MOR in acidic media.

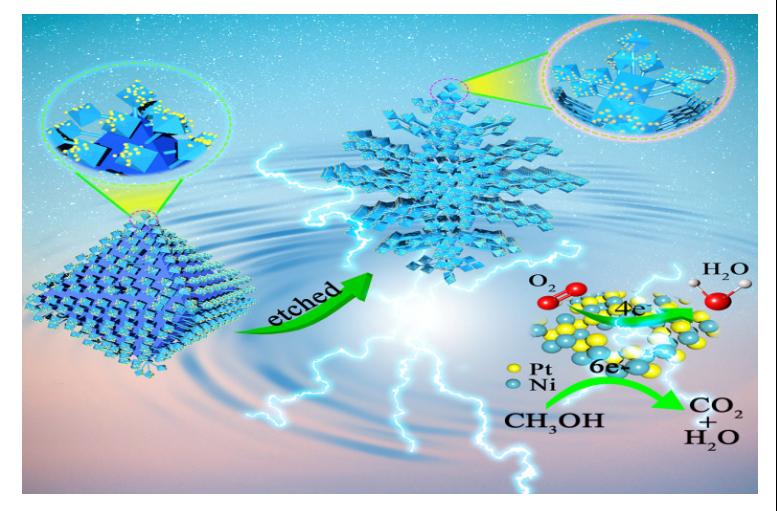

[5] N. Abdullah, S. K. Kamarudin, L. K. Shyuan, Nanoscale Res. Lett., 2018, 13, 90.

[6] J. Huang, C. Ding, Y. Yang, G. Liu, W.-B. Cai, Chin. J. Catal., 2019, 40, 1895-1903.

[7] H. Du, K. Wang, P. Tsiakaras, P. K. Shen, Appl. Catal. B, 2019, 258, 117951.

[8] X. Song, S. Luo, X. Fan, M. Tang, X. Zhao, W. Chen, Q. Yang, Z. Quan, Front. Chem., 2018, 6, 468.

[9] X.-F. Zhang, H.-B. Meng, H.-Y. Chen, J.-J. Feng, K.-M. Fang, A.-J. Wang, J. Alloys Compd., 2019, 786, 232-239.

[10] L. Bu, N. Zhang, S. Guo, X. Zhang, J. Li, J. Yao, T. Wu, G. Lu, J.-Y. Ma, D. $\mathrm{Su}, \mathrm{X}$. Huang, Science, 2016, 354, 1410-1414.

[11] H. Du, S. Luo, K. Wang, M. Tang, R. Sriphathoorat, Y. Jin, P. K. Shen, Chem. Mater., 2017, 29, 9613-9617.

[12] K. Wang, H. Du, R. Sriphathoorat, P. K. Shen, Adv. Mater., 2018, 30, 1804074.

[13] S. Chen, S. Thota, X. Wang, J. Zhao, J. Mater. Chem. A, 2016, 4, 9038-9043.

[14] R. Wu, Y. Li, W. Gong, P. K. Shen, ACS Sustain. Chem. Eng. 2019, 7, 8419-8428.

[15] H. Kwon, M. K. Kabiraz, J. Park, A. Oh, H. Baik, S.-I. Il Choi, K. Lee, Nano Lett., 2018, 18, 2930-2936.

[16] C. Cui, L. Gan, H.-H. Li, S.-H. Yu, M. Heggen, P. Strasser, Nano Lett., 2012, 12, 5885-5889.

[17] L. Dubau, T. Asset, R. Chattot, C. Bonnaud, V. Vanpeene, J. Nelayah, F. Maillard, ACS Catal., 2015, 5, 5333-5341.

[18] L. Gan, C. Cui, M. Heggen, F. Dionigi, S. Rudi, P. Strasser, Science, 2014, 346, 1502-1506.

[19] C. Wang, L. Zhang, H. Yang, J. Pan, J. Liu, C. Dotse, Y. Luan, R. Gao, C. Lin, J. Zhang, J. P. Kilcrease, X. Wen, S. Zou, J. Fang, Nano Lett., 2017, 17, 2204-2210.

[20] Z. Cao, Q. Chen, J. Zhang, H. Li, Y. Jiang, S. Shen, G. Fu, B. Lu, Z. Xie, L. Zheng, Nat. Commun., 2017, 8, 15131.

[21] W. Gong, Z. Jiang, L. Huang, P. K. Shen, Int. J. Hydrogen Energy, 2018, 43, 18436-18443.

[22] Y. Wang, M. Yi, K. Wang, S. Song, Chin. J. Catal., 2019, 40, 523-533.

[23] J. Li, J. Chen, H. Wan, J. Xiao, Y. Tang, M. Liu, H. Wang, Appl. Catal. B, 2019, 242, 209-217.

[24] X. Sun, K. Jiang, N. Zhang, S. Guo, X. Huang, ACS Nano, 2015, 9, 7634-7640.
[25] R. Loukrakpam, B. N. Wanjala, J. Yin, B. Fang, J. Luo, M. Shao, L. Protsailo, T. Kawamura, Y. Chen, V. Petkov, C.-J. Zhong, ACS Catal., 2011, 1, 562-572.

[26] G. Fu, H. Liu, N. You, J. Wu, D. Sun, L. Xu, Y. Tang, Y. Chen, Nano Res., 2016, 9, 755-765.

[27] A. Oh, H. Baik, D. S. Choi, J. Y. Cheon, B. Kim, H. Kim, S. J. Kwon, S. H. Joo, Y. Jung, K. Lee, ACS Nano, 2015, 9, 2856-2867.

[28] R. Sriphathoorat, K. Wang, P. K. Shen, ACS Appl. Energy Mater., 2019, 2, 961-965.

[29] Y. Chen, G. Fu, Y. Li, Q. Gu, L. Xu, D. Sun, Y. Tang, J. Mater. Chem. A, 2017, 5, 3774-3779.

[30] Y. Ma, L. Miao, W. Guo, X. Yao, F. Qin, Z. Wang, H. Du, J. Li, F. Kang, L. Gan, Chem. Mater., 2018, 30, 4355-4360.

[31] X.-L. Chen, L. Zhang, J.-J. Feng, W. Wang, P.-X. Yuan, D.-M. Han, A.-J. Wang, J. Colloid Interface Sci., 2018, 530, 394-402.

[32] Y. Yu, Q. Zhang, X. Lu, J. Y. Lee, J. Phys. Chem. C, 2010, 114, 11119-11126.

[33] R. Wu, P. Tsiakaras, P. K. Shen, Appl. Catal. B, 2019, 251, 49-56.

[34] L. Huang, M. Wei, N. Hu, P. Tsiakaras, P. K. Shen, Appl. Catal. B, 2019, 258, 117974.

[35] K. Bhunia, S. Khilari, D. Pradhan, Dalton Trans., 2017, 46, 15558-15566.

[36] Y. S. Kang, D. Choi, H.-Y. Park, S. J. Yoo, J. Ind. Eng. Chem., 2019, 78, $448-454$

[37] W. Gong, Z. Jiang, R. Wu, Y. Liu, L. Huang, N. Hu, P. Tsiakaras, P. K. Shen, Appl. Catal. B, 2019, 246, 277-283.

[38] J. Liang, Z. Miao, F. Ma, R. Pan, X. Chen, T. Wang, H. Xie, Q. Li, Chin. J. Catal., 2018, 39, 583-589.

[39] X.-Y. Huang, X.-Y. Zhu, X.-F. Zhang, L. Zhang, J.-J. Feng, A.-J. Wang, Electrochim. Acta, 2018, 271, 397-405.

[40] Y. Zhao, L. Fan, J. Ren, B. Hong, Int. J. Hydrogen Energy, 2014, 39, 4544-4557.

[41] R. Sriphathoorat, K. Wang, S. Luo, M. Tang, H. Du, X. Du, P. K. Shen, J. Mater. Chem. A, 2016, 4, 18015-18021.

[42] S. Lu, H. Li, J. Sun, Z. Zhuang, Nano Res., 2018, 11, 2058-2068.

[43] Z. Jiang, Y. Liu, L. Huang, W. H. Gong, P. K. Shen, ACS Sustain. Chem. Eng., 2019, 7, 8109-8116.

[44] E. V. Shevchenko, D. V. Talapin, A. L. Rogach, A. Kornowski, M. Haase, H. Weller, J. Am. Chem. Soc., 2002, 124, 11480-11485.

[45] X. Du, S. Luo, H. Du, M. Tang, X. Huang, P. K. Shen, J. Mater. Chem. A, 2016, 4, 1579-1585. 
[46] H. Zhao, Z.-P. Hu, Y.-P. Zhu, L. Ge, Z.-Y. Yuan, Chin. J. Catal., 2019, 40, 1366-1374.

[47] Y. Li, W. Pei, J. He, K. Liu, W. Qi, X. Gao, S. Zhou, H. Xie, K. Yin, Y. Gao, J. He, J. Zhao, J. Hu, T.-S. Chan, Z. Li, G. Zhang, M. Liu, ACS Catal.,
2019, 9, 10870-10875.

[48] H. Jiang, J. Gu, X. Zheng, M. Liu, X. Qiu, L. Wang, W. Li, Z. Chen, X. Ji, J.

Li, Energy Environ. Sci., 2019, 12, 322-333.

[49] X. Yan, Y. Jia, L. Zhang, X. Yao, Chin. J. Catal., 2017, 38, 1011-1020.

\title{
分级骨架和多层的Pt-Ni纳米晶体用于高效氧还原和甲醇氧化反应
}

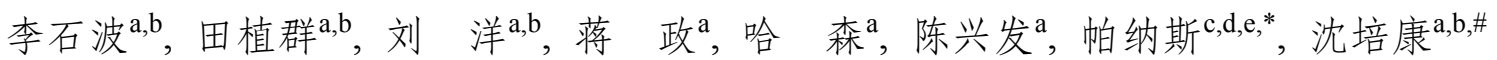 \\ a广西大学化学化工学院, 广西电化学能源材料重点实验室, 广西大学可持续能源材料中心, 广西南宁530004, 中国 \\ b广西大学有色金属与材料新加工技术重点实验室, 南宁530004, 中国 \\ c高温电化学研究所, 叶卡捷琳堡620990, 俄罗斯 \\ d乌拉尔联邦大学, 叶卡捷琳堡620002, 俄罗斯 \\ e 塞萨莉大学机械工程系, 能源转换实验室, 希腊 38834
}

\begin{abstract}
摘要: 燃料电池是电动汽车和电子设备最有前途的清洁能源之一. Pt催化剂在氧还原反应(ORR)和甲醇氧化反应(MOR)中 的电催化性能对电池系统的能源效率和电池的价格起着至关重要的作用, 因此设计高效的电催化剂以最大限度地提高铂 的利用率, 从而增强电催化效果、降低成本, 已经成为燃料电池发展的一个重要方向. 早期的研究表明, 铂基催化剂可以有 效地提高电催化性能, 并且它们的组成和形貌被认为是影响催化剂活性的两个关键因素. 至今, 已合成出各种各样的Pt基 催化剂, 如 $\mathrm{Pt}-\mathrm{Pb} / \mathrm{Pt}$ 核壳纳米盘、 $\mathrm{Pt}_{3} \mathrm{Co}$ 凹面立方体、Pt-Cu-Rh纳米笼、Pt-Pd纳米枝晶等, 其中纳米枝晶结构的催化剂表现出 很好的氧还原性能, 其高效的催化活性被认为是暴露出的较高的比表面积促进了电子转移以及拥有较多的Pt活性位点. 本 文采用简单的溶剂热法合成了具有大比表面积的Pt-Ni分层骨架结构(Pt-Ni HSNs)催化剂, 为了验证反应物所起的作用, 通 过收集不同反应时间下的产物和控制单一变量, 我们发现在合成配方中加入 $\mathrm{H}_{2} \mathrm{SO}_{4}$ 是此类Pt-Ni纳米晶体成功生长的关键 触发因素. 在 $\mathrm{H}_{2} \mathrm{SO}_{4}$ 的诱导下, $\mathrm{Pt}$ 和 $\mathrm{Ni}$ 原子倾向于沉积在(111)面, 促使Pt-Ni合金沿晶面方向生长为八面体结构, 在此过程中 发生了粒子自组装成长以及相分离过程, 最后我们用酸蚀法制造了 Pt-Ni HSNs, 并通过TEM, XRD和XPS表征其微观结构 及组成, 证实了Pt-Ni HSNs已经形成合金结构.

在酸性条件下, Pt-Ni HSNs在ORR反应中展示出比商业 $\mathrm{Pt} / \mathrm{C}$ 更好的活性. 在 $0.9 \mathrm{~V}$ 时的质量活性为 $1.25 \mathrm{~A} \mathrm{mg}_{\mathrm{pt}}{ }^{-1}$, 是商业 $\mathrm{Pt} / \mathrm{C}$ 质量活性的 8.9 倍, 并且在 10000 圈的耐久性测试中, Pt-Ni HSNs的质量活性仅仅损失了 $21.6 \%$, 远低于 $\mathrm{Pt} / \mathrm{C}$ 损失的活性比 例. Tafel曲线和旋转环盘测试结果表明, Pt-Ni HSNs在ORR反应中发生的是4电子过程, 证实了它的高活性. 另外, 在酸性 溶液中, Pt-Ni HSNs表现出了比商业Pt/C更好的MOR催化活性, 且抗CO中毒能力更强. 这可归因于两点: (1) Pt-Ni HSNs是 由多个小颗粒组装而成, 大大提高了与电解液的接触面积; (2) 它独特的骨架结构减少了颗粒间团聚的可能性, 有利于质子 的转移. 本文为设计先进的铂基电催化剂提供了一种新的自组装方法.
\end{abstract}

关键词: Pt-Ni分层骨架结构; 自组装; 溶剂热法; 氧还原; 甲醇氧化; 燃料电池; 活性

收稿日期: 2020-05-11. 接受日期: 2020-06-20. 上网日期: 2020-09-05.

*通讯联系人. 电子信箱: tsiak@mie.uth.gr

\#通讯联系人. 电子信箱: pkshen@gxu.edu.cn

基金来源：国家重点研究开发计划(2017YFB0103001); 国家自然科学基金与福建省自然科学基金(U1705252); 广西科技项目 (AA17204083, AB16380030); 广西研究生教育创新项目(YCBZ2019012).

本文的电子版全文由Elsevier出版社在ScienceDirect上出版(http://www.sciencedirect.com/science/journal/18722067). 